\title{
Midterm follow-up of penetrating ulcer and intramural hematoma of the aorta
}

\author{
Shawn L. Tittle, MD \\ Raymond J. Lynch, BS ${ }^{\text {a }}$ \\ Patricia E. Cole, MD ${ }^{\mathrm{b}}$ \\ Harsimran S. Singh, BS ${ }^{a}$ \\ John A. Rizzo, PhD ${ }^{\mathrm{c}}$ \\ Gary S. Kopf, MD \\ John A. Elefteriades, MD ${ }^{a}$
}

From the Section of Cardiothoracic Surgery $^{\mathrm{a}}$ and the Department of Diagnostic Imaging,, Yale University, New Haven, Conn, and the Department of Epidemiology, ${ }^{\mathrm{c}}$ Ohio State University, Columbus, Ohio.

Read at the Eighty-first Annual Meeting of The American Association for Thoracic Surgery, San Diego, Calif, May 6-9, 2001.

Received for publication May 14, 2001; revisions requested June 26, 2001; revisions received Sept 10, 2001; accepted for publication Oct 25, 2001.

Address for reprints: John A. Elefteriades, MD, 333 Cedar St, 121 FMB, New Haven, CT 06510 (E-mail: john.elefteriades@yale. edu).

J Thorac Cardiovasc Surg 2002;123:1051-9

Copyright () 2002 by The American Association for Thoracic Surgery

$0022-5223 / 2002 \$ 35.00+0 \quad \mathbf{1 2 / 6 / 1 2 1 6 8 1}$

doi:10.1067/mtc.2002.121681
Objective: Most studies on variant forms of aortic dissection-penetrating ulcer and intramural hematoma-have focused on the initial presenting episode, with scant follow-up. This investigation provides midterm follow-up of penetrating ulcer and intramural hematoma to determine whether the aorta shows healing according to radiography, goes on to dilate, or tends to rupture during later follow-up.

Methods: Forty-five patients with penetrating ulcers $(\mathrm{n}=26)$ or intramural hematomas $(\mathrm{n}=19)$ were treated at our institution. Ten patients with penetrating ulcers were male and 16 were female, and their ages ranged from 54 to 87 years (mean 72 years). Eight patients with intramural hematomas were male and 11 were female, and their ages ranged from 54 to 88 years (mean 74 years). These patients all had symptoms of aortic disease. Patients with incidental imaging findings were not considered.

Results: In the group with penetrating ulcers, rupture occurred during the initial admission in $10(38 \%)$ cases, 17 patients (65\%) underwent surgery, and 22 patients $(85 \%)$ survived to hospital discharge. Among those with intramural hematomas, rupture occurred during the initial admission in 5 cases (26\%), 7 patients (37\%) underwent surgery, and 16 patients (84\%) survived to hospital discharge. Follow-up ranged from 1 month to 12.5 years (mean 3.4 years). No ischemic vascular complications occurred. Imaging follow-up was available for 26 of the 45 patients. Of these, $19 \%$ of lesions showed resolution, $23 \%$ had worsened, $39 \%$ had progressed to typical dissection, and $19 \%$ were unchanged. Six late deaths were known to be caused by rupture. In the group with penetrating ulcers, aortic diameter increased from 4.8 to $5.1 \mathrm{~cm}$ during the course of 14 months. In the group with intramural hematomas, aortic diameter increased from 5.3 to $5.9 \mathrm{~cm}$ during the course of 21 months. Overall survivals were $80 \%$ at 1 year, $73 \%$ at 3 years, and $66 \%$ at 5 years.

Conclusions: Intramural hematoma and penetrating ulcer are lesions associated with advanced age. Women predominate. Penetrating ulcer and intramural hematoma rupture both early and late. Radiographically documented worsening, improvement, or frank dissection may occur with time. Aortic growth does occur $(0.2 \mathrm{~cm}$ per year for penetrating ulcer and $0.4 \mathrm{~cm}$ per year for intramural hematoma). Vascular ischemic complications do not occur. Because of the high early rupture rate, the frequency of radiographic worsening, and the documented occurrence of late rupture, we now recommend surgical replacement of the aorta for these virulent vascular lesions as long as the patient's comorbidities do not preclude surgical intervention. 


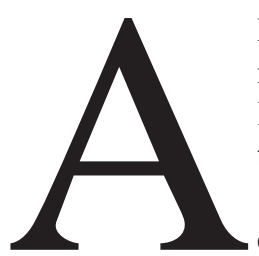

lthough Shennan ${ }^{1}$ first described penetrating atheromatous ulcers in 1934 and Krukenberg ${ }^{2}$ described intramural hematoma as dissection without flap as early as 1920 , the widespread recognition of penetrating ulcer and intramural hematoma of the thoracic aorta is a product of the current era of 3-dimensional aortic imaging. Penetrating ulcers of the aorta are ulcerations in the aortic wall thought to be caused by rupture of an atheromatous plaque through the internal elastic lamina, with subsequent localized medial disruption and potential rupture (Figure 1). ${ }^{3}$ Intramural hematoma is a localized collection of blood in the media of the aorta, most likely as a result of hemorrhage from the vasa vasorum. These entities do not have intimal flaps or false lumens, and whereas penetrating ulcers may be visualized during conventional angiography, intramural hematomas are not usually visualized with this study. Today these clinical diagnoses are products of modern radiologic imaging techniques. Before modern imaging, specifically computed tomographic scan with contrast, magnetic resonance imaging, and transesophageal echocardiography, most of these diagnoses were made by pathologists at autopsy.

Previous work has characterized the initial presentations and early outcomes of penetrating ulcer and intramural hematoma. Our group recognized the aggressive nature of penetrating ulcer, differentiating its early behavior from that of classic type A and B dissections..$^{4,5}$ The percentage of patients with acute rupture was $40 \%$ for penetrating ulcer, compared with $7 \%$ for type A dissection and 3.6\% for type B dissection. Of course, routine urgent surgical therapy for acute type A dissection prevents this lesion from manifesting its full rupture potential. Presenting characteristics of intramural hematoma are also described in the literature, with conflicting data regarding natural history. Some have suggested that intramural hematoma has a clinical course identical to that of dissection, whereas others have described a distinct course.$^{6-8}$ Differences abound in recommendations for surgical versus medical management. ${ }^{9,10}$

Currently most information available in the literature regarding penetrating ulcer and intramural hematoma of the aorta is limited to the initial presentation and hospitalization. Few data are available for the subsequent natural history of the disease beyond the initial presentation. Thus a number of unanswered questions remain. What is the behavior of these lesions with time? Does healing or progression to dissection take place? Does the aorta with a penetrating ulcer or intramural hematoma dilate with time? Do these lesions rupture later in their course? Do these patients acquire vascular problems similar to those in aortic dissection? How should these lesions be managed, operatively or nonoperatively?

This article reviews a cohort of patients from our center

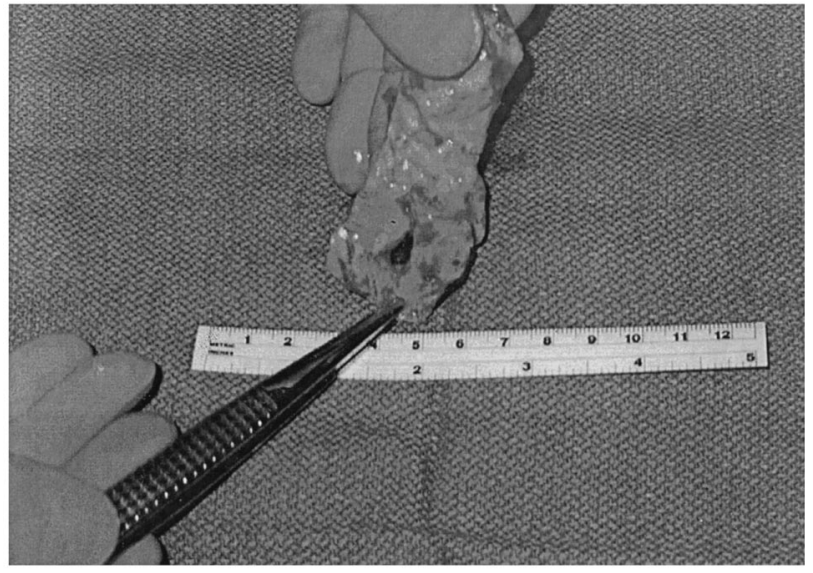

Figure 1. Photograph of resected penetrating ulcer of thoracic aorta. Note similarity in appearance to duodenal ulcer.

to midterm follow-up. The aim is to define the natural histories of these two entities during the first several years after presentation.

\section{Methods}

Records of a total of 45 patients, 26 patients with penetrating ulcers and 19 patients with intramural hematomas, were retrospectively reviewed from the database of the Yale Center for Thoracic Aortic Disease. These records were identified from among those of 360 patients treated for acute dissecting-type diseases. The study patients constituted a subset of this group with acute presentation, and lesions found incidentally were not included in this study.

The follow-up consisted of chart review, examination of the computerized radiologic database, telephone calls, and Internet (Social Security Death Index) and medical record mortality review. The chart review involved collection of data regarding presentation, initial symptoms, radiologic studies, interventions (if any), in-hospital mortality, and subsequent course. The radiologic review involved systematic reexamination of all Yale and outside patient films, at presentation and subsequent, by a single vascular radiologist (P.E.C.) and a single cardiothoracic surgeon (J.A.E.). The clinical and radiographic criteria used to diagnose the diseases were as follows:

- If an intimal flap was present, the pathologic entity was considered a typical dissection, and no diagnosis of penetrating ulcer or intramural hematoma was made.

- Penetrating ulcer took precedence over intramural hematoma. If an ulcer with surrounding hematoma was seen, the lesion was considered a penetrating ulcer. This is thought to reflect the two different etiologies, ruptured plaque as opposed to bleeding from the vasa vasorum. We did not differentiate between "small" and "giant" ulcers, but the patients we describe here all had symptoms of aortic disease. These pathologic conditions were not incidental findings on routine examinations done for other reasons.

- Concentric shadowing abnormalities in the aortic wall were diagnosed as intramural hematomas.

- Films from the initial presentation were used to make the classifying diagnosis. If an intramural hematoma went on to 
ulcerate, or a hematoma formed around an ulcer, the original diagnosis was maintained for classification.

- Only patients with acute presentations were included in this study.

- When available, operative and autopsy findings took precedence over any and all radiologic findings.

The definitions of disease healing, progression to dissection, worsening and rupture were as follows:

- Healing was considered to have occurred if aortic diameter or wall thickness decreased.

- In progression to dissection, a typical flap developed in the aorta, defining two lumens.

- Worsening was considered to have occurred if aortic diameter increased, wall thickness increased, ulcer size increased, or the wall under the ulcer became attenuated.

- Rupture was determined by the presence of extra-aortic blood according to computed tomographic scan, surgical exploration, or postmortem examination. Diagnosis of rupture after discharge was based on death certificates or clinical circumstances. Rupture percentages are for occurrence of these events during the initial hospital admission.

Follow-up was $100 \%$ complete.

\section{General Approach to these Lesions}

Our general policy, which was based on our early experience and the available literature, was to operate on all ascending penetrating ulcers and hematomas and to treat those in the descending aorta with standard anti-impulse therapy, with a low threshold for surgical intervention in cases of recurrent clinical symptoms or radiographic progression. Patients who were not operative candidates for general reasons (age, comorbidities, patient preference) were excluded from this general paradigm.

\section{Results}

\section{Behavior of Penetrating Ulcer (Figure 2)}

Twenty-six patients with penetrating ulcers were studied. The average age of the patients was 72 years (range 54-85 years), and $62 \%$ were female. Of the 26 patients, 10 (38\%) had rupture at admission. Seventeen patients $(67 \%)$ were operated on. Twenty-two patients (87\%) survived to discharge. The $38 \%$ incidence of rupture at presentation among these patients was significantly higher than that among our registry data for patients with typical aortic dissections, who had rupture rates of $8 \%$ and $4 \%$ for type $\mathrm{A}$ and $\mathrm{B}$ dissections, respectively $(P<.01)$. The lesion was present in the ascending aorta in 12 patients $(46 \%)$ and in the descending aorta in $14(54 \%)$. Eleven patients (42\%) had no imaging follow-up of the penetrating ulcer. Of those patients, 6 underwent surgery, 2 died, and 3 had only the initial imaging study performed. Fifteen patients (58\%) had follow-up imaging. Of these, 4 (27\%) had no change, 4 (27\%) had worsening (Figure 3), and 7 (46\%) had progression to frank dissection. The mean interval to detection of progression to frank dissection was 12.0 months (range 0.1-50.8 months). Seventy-three percent showed worsening in one form or another, and the remainder showed no change. This type of

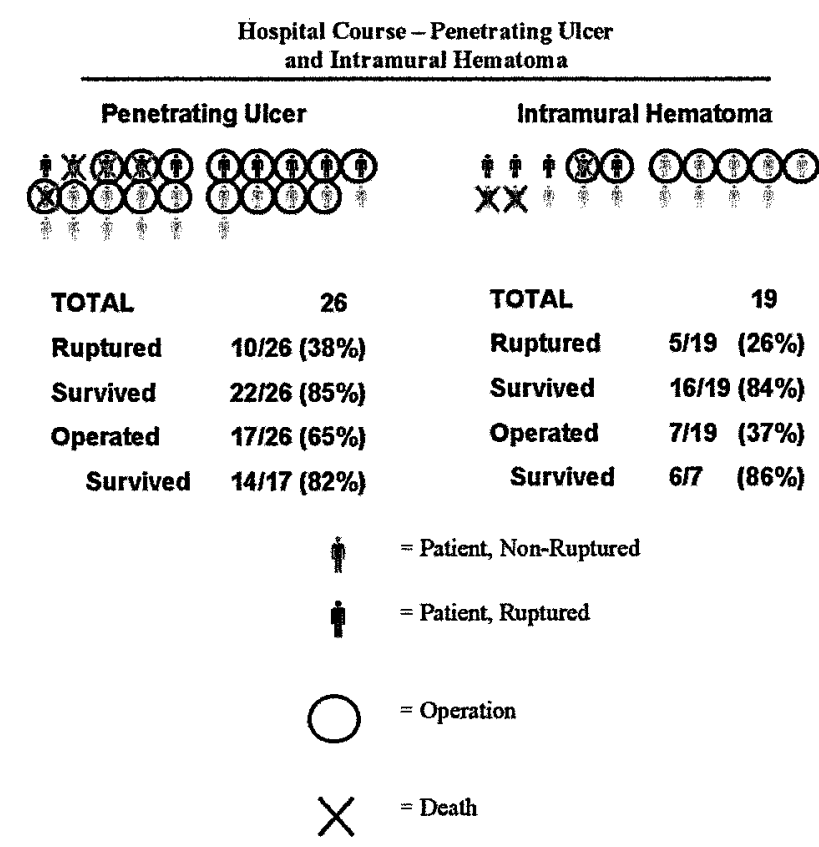

Figure 2. Hospital courses of penetrating ulcer and intramural hematoma. Dark figures represent patients with rupture; light figures represent patients without rupture; circles indicate operation; and $X s$ indicate death.

lesion did not resolve. The aortas in these patients grew at the rate of $0.2 \mathrm{~cm} / \mathrm{y}$. Mean aortic size was $4.8 \mathrm{~cm}$ at presentation and $5.1 \mathrm{~cm}$ at latest follow-up (mean 18.2 months). Average follow-up for these patients was 3.4 years (4.1 years, excluding those with in-hospital deaths), with a range of 0.1 to 12.5 years for patients who survived hospitalization.

Seven patients with penetrating ulcers died during late follow-up. One patient (14\%) died of documented rupture. This was a surgical patient who had rupture of a nonreplaced segment of the abdominal aorta. Other causes of death were myocardial infarction $(\mathrm{n}=2,29 \%)$, cerebrovascular accident $(\mathrm{n}=1,14 \%)$, chronic obstructive pulmonary disease $(\mathrm{n}=1,14 \%)$, and unspecified noncardiovascular cause $(\mathrm{n}=2,29 \%)$.

\section{Behavior of Intramural Hematoma (Figure 2)}

Nineteen patients with intramural hematomas were studied. The average age of the patients was 74 years (range 54-88 years), and 58\% were female. Of the 19 patients, 5 (26\%) had rupture at admission. Seven patients (37\%) were operated on. Sixteen patients (84\%) survived to discharge. Incidence of early rupture among these patients was $26 \%$, compared with $8 \%$ and $4 \%$ for type A and B dissections, respectively $(P<.01)$. The lesion was present in the ascending aorta in 11 patients $(58 \%)$ and in the descending aorta in $8(42 \%)$. Eight patients $(42 \%)$ had no imaging follow-up of the intramural hematoma. Of those patients, 4 

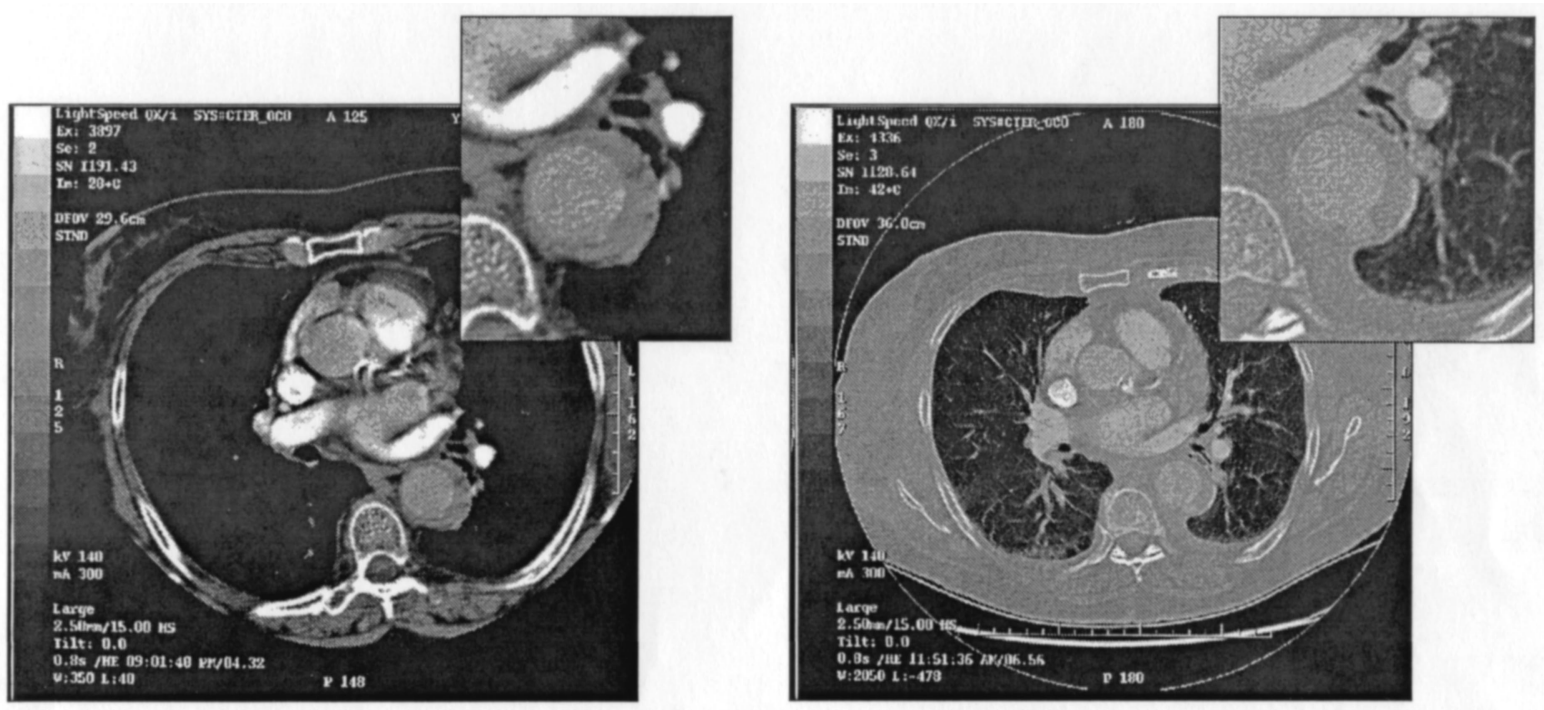

Figure 3. Radiographic (computed tomographic scan) evidence of worsening of penetrating ulcer. Left, Initial scan. Right, Scan after elapsed time of 3 weeks. Note increased size and depth of ulcer at 5 o'clock position in both insets.

underwent surgery, 3 died, and 1 had only the initial imaging study performed. Eleven patients $(58 \%)$ had follow-up imaging. Of these, 5 (46\%) had healing, 1 (9\%) had no change, 2 (18\%) had worsening (Figure 4), and 3 (27\%) had progression to frank dissection. Fifty-four percent showed either worsening or no change, and $46 \%$ showed healing. The aortas in these patients grew at the rate of $0.4 \mathrm{~cm} / \mathrm{y}$. Mean aortic size was $5.3 \mathrm{~cm}$ at presentation and $5.8 \mathrm{~cm}$ at latest follow-up (mean 15.6 months). Average follow-up in these patients was 3.4 years (4.0 years, excluding those with in-hospital deaths), with a range of 0.3 to 9.3 years for patients who survived hospitalization.

Eight patients with intramural hematomas died during late follow-up. Five deaths (63\%) were due to documented rupture. Other causes of late death were myocardial infarction $(\mathrm{n}=1,12 \%)$, pneumonia $(\mathrm{n}=1,12 \%)$, and unspecified noncardiovascular cause $(\mathrm{n}=1,12 \%)$.

\section{Behavior of the Whole Cohort}

A total of 45 patients were studied (Table 1). The average age of the patients was 73 years (range 54-88 years), and $60 \%$ were female. This female preponderance was significantly different from the sex distribution in our overall dissection registry, in which only $38 \%$ of patients were female $(P<.01)$. Of the 45 patients, $15(33 \%)$ had rupture at admission. Twenty-four patients (53\%) were operated on. Eighty-three percent of penetrating ulcers in the ascending aorta required operation, and $50 \%$ in the descending aorta required operation. Forty-five percent of intramural hematomas in the ascending aorta required operation, and $25 \%$ in the descending aorta required operation. All operations were urgent or emergency. Twenty of 24 patients (83\%) survived after operation to discharge. By comparison, 18 of 21 nonoperatively treated patients $(86 \%)$ survived to discharge. In total, 38 patients (84\%) survived to hospital discharge. Nineteen patients (42\%) had no imaging follow-up of the lesion. Of those patients, 10 underwent surgery, 5 died, and 4 had only the initial imaging study performed. Twenty-six patients (58\%) had follow-up imaging. This represents $87 \%$ of those patients still living who did not have the lesion excised surgically. Of these, 5 had healing, 5 had no change, 6 had worsening, and 10 had progression to frank dissection. Average follow-up of these patients was 3.4 years (4.1 years, excluding those with in-hospital deaths), with a range of 0.1 to 12.5 years for patients who survived hospitalization.

\section{Survival Curves}

The slope of the mortality curve decreased abruptly once the initial phase of presentation was surpassed (Figure 5, A). Penetrating ulcer and intramural hematoma had similar outlooks. Surgical intervention appeared to produce a survival similar to or exceeding that of the less severely ill medically treated patients, at least for intramural hematoma (Figure 5, $B$ and $C$ ). Strict comparison is not feasible, because surgical bias may have selected patients at better risk from among these elderly patients with abundant comorbidities. Overall survivals were $80 \%$ at 1 year, $73 \%$ at 3 years, and $66 \%$ at 5 years.

\section{Discussion}

During the past 20 years, the diagnoses of penetrating ulcer and intramural hematoma of the aorta have become better recognized and more distinct from the larger universe of 

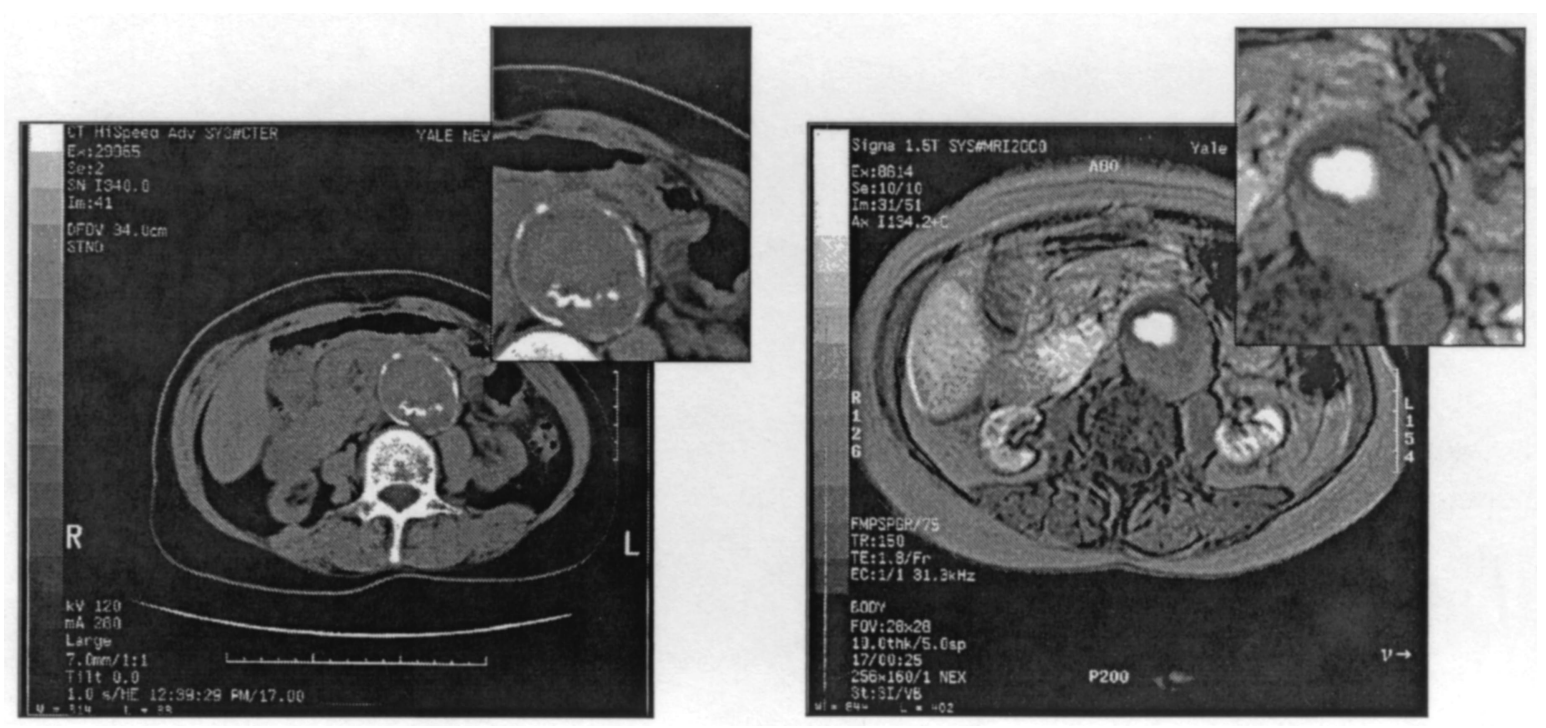

Figure 4. Radiographic evidence of worsening of intramural hematoma. Left, Initial computed tomographic scan shows calcium in aortic wall. Right, Magnetic resonance image after elapsed time of 19 weeks shows marked increase in hematoma size outside aortic lumen.

typical dissection. Unique pathophysiologic characteristics and natural history are being elucidated. Specifically, these entities appear to occur without the intimal flap that accompanies classic aortic dissection. Care must be taken to differentiate these two diseases from dissection, because both short- and long-term courses appear to involve considerable risk of early rupture and concomitant late death.

Although this is one of the larger series in terms of patient numbers, with 45 initial patients, there was attrition before natural history follow-up as a result of mortality and selection for operation. The observations regarding presenting pathologic characteristics and early lesion behavior are based on the total group. Those regarding imaging follow-up were based on a subgroup of 26 patients. Thus observations and recommendations must be considered provisory, as worldwide experience with these entities accumulates.

Previous case series ${ }^{7-13}$ have included mean follow-up times of 37 days to 29 months. This report extends the follow-up of penetrating ulcer and intramural hematoma to a mean follow-up of 41 months (49 months, excluding in-hospital deaths). This permits observations about the midterm sequelae of these aortic lesions.

The female preponderance seen in this series is in marked contradistinction to the sex distribution among our patients with typical dissections, who were $62 \%$ male and $38 \%$ female. This preponderance is at odds with patterns of most cardiovascular diseases. The reasons that women were more frequently affected are unknown. Also, this study indicates that penetrating ulcer and intramural hematoma are diseases of advanced age (mean 72 and 74 years, respectively).
TABLE 1. Characteristics of penetrating ulcers and intramural hematomas according to anatomic location

\begin{tabular}{llll}
\hline & $\begin{array}{c}\text { Penetrating } \\
\text { ulcer }\end{array}$ & $\begin{array}{c}\text { Intramural } \\
\text { hematoma }\end{array}$ & Total \\
\hline Ascending & & & \\
$\quad$ All lesions & $46 \%(n=12)$ & $58 \%(n=11)$ & $51 \%(n=23)$ \\
$\quad \begin{array}{l}\text { Rupture } \\
\quad \text { Operation }\end{array}$ & $33 \%(n=4)$ & $18 \%(n=2)$ & $26 \%(n=6)$ \\
Descending & $83 \%(n=10)$ & $45 \%(n=5)$ & $65 \%(n=15)$ \\
$\quad \begin{array}{ll}\text { All lesions } \\
\text { Rupture }\end{array}$ & $54 \%(n=14)$ & $42 \%(n=8)$ & $49 \%(n=22)$ \\
$\quad$ Operation & $50 \%(n=7)$ & $25 \%(n=2)$ & $41 \%(n=9)$ \\
Total & & & \\
$\quad$ Rupture & $38 \%(n=10)$ & $26 \%(n=5)$ & \\
$\quad$ Operation & $65 \%(n=17)$ & $37 \%(n=7)$ & \\
\hline
\end{tabular}

A high incidence of rupture at initial presentation of penetrating ulcer $(38 \%)$ and intramural hematoma (26\%) was once again confirmed in this study. This rate was significantly higher than that among our patients with typical type A and type B dissections, who had rupture at the rates of $8 \%$ and $4 \%$, respectively. This confirms that penetrating ulcers and intramural hematomas are serious lesions. It is clear that a low threshold for surgical intervention should be maintained.

It is interesting that no branch vascular occlusion occurred in any patients in this series. This is reflective of the fact that there is no flap and no false lumen in these conditions. 

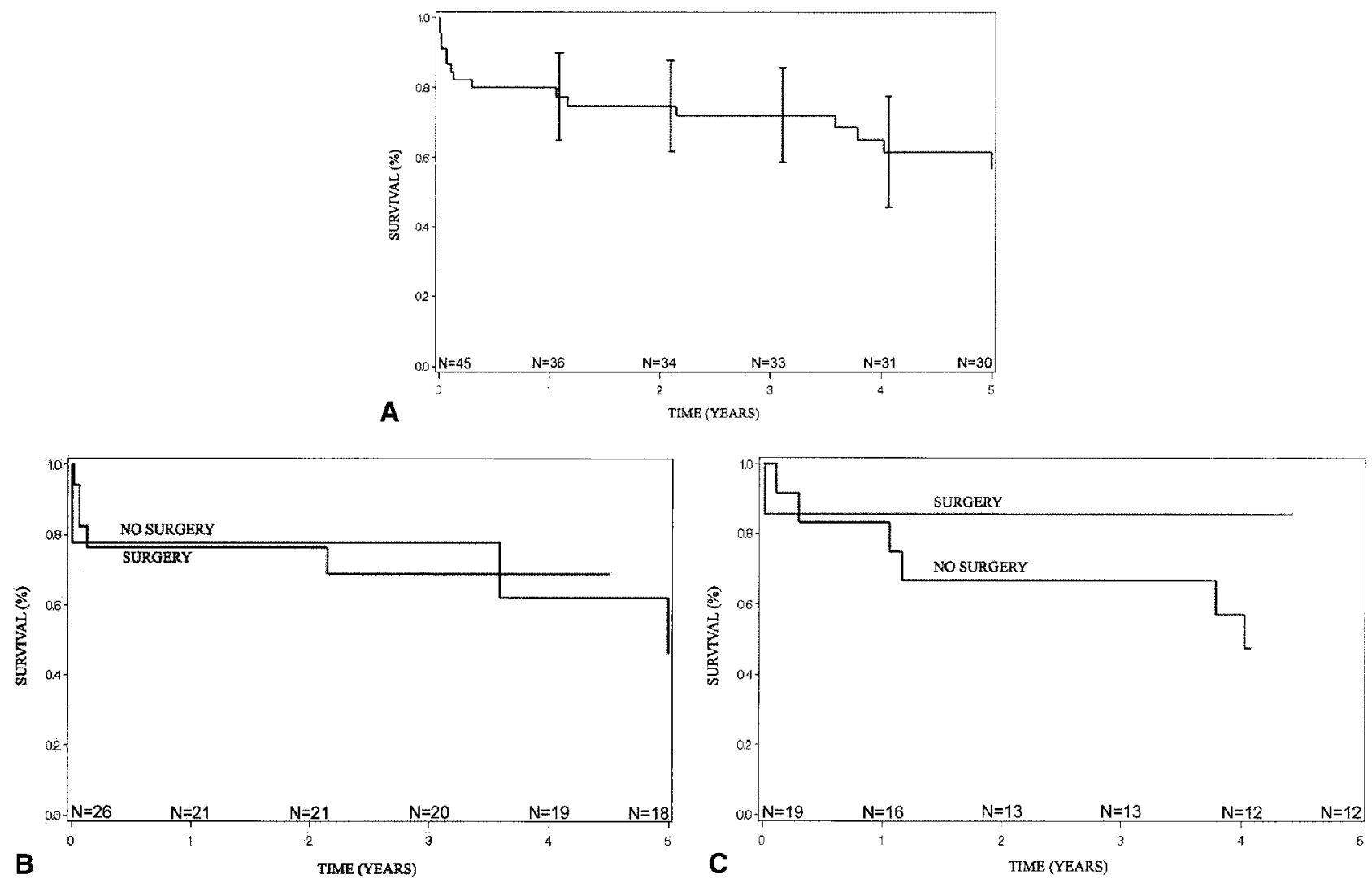

Figure 5. Kaplan-Meier survival curves. A, All patients in the study. Error bars indicate SD. B, Patients with penetrating ulcer. C, Patients with intramural hematoma.

We had expected that penetrating ulcers would be less likely to progress to dissection in the long-term, because of the protection afforded by the local atherosclerosis, but this was not the case. Nearly half of these lesions progressed to typical dissection during longitudinal follow-up.

Our key observations on the basis of these follow-up data are as follows:

1. There was an unexplained female predominance in penetrating ulcer and intramural hematoma.

2. Ruptures of penetrating ulcer and intramural hematoma were common, both early and late. Thirty-eight percent of penetrating ulcers and $26 \%$ of intramural hematomas were ruptured at initial presentation. This risk of early rupture was higher than that for typical aortic dissection. Both diseases also had a propensity toward late rupture. Intramural hematoma showed an especially high propensity toward late rupture ( 2 in the ascending aorta, 3 in the descending aorta), whereas patients with penetrating ulcers often died of comorbidities. Fourteen percent of late deaths among patients with penetrating ulcers were due to rupture, as were $63 \%$ of late deaths among patients with intramural hematomas.
3. In follow-up, healing, worsening, and progression to typical aortic dissection occurred with time. These possibilities warrant regular radiographic follow-up in such cases.

4. Aortic growth did occur in patients with penetrating ulcers and intramural hematomas, at rates of 0.2 and $0.4 \mathrm{~cm} / \mathrm{y}$, respectively.

5. Unlike with typical dissection, vascular complications did not occur with penetrating ulcer and intramural hematoma. There were no instances of early or late branch organ occlusion related to the aortic process in any patients in this study.

6. This review resulted in a change in our policy protocols for management of penetrating ulcer and intramural hematoma of the aorta. Our policy is independent of the location of the lesion, whether in the ascending or descending aorta, and of the diameter of the aorta. The high rates of rupture at presentation, the frequency of worsening on serial radiographic followup, and the continued incidence of death from rupture despite medical management attest to the virulence of these lesions. We now consider these lesions to be preferentially surgically treated, provided that the pa- 
tient's overall condition permits aggressive therapy. We recommend immediate operation for patients with realized or impending rupture on radiographic or clinical grounds and semielective repair for more patients with more stable lesions. These recommendations are intended for patients with acutely presenting penetrating ulcers and intramural hematomas, as in our series, not for patients in whom such lesions are found on incidental or routine imaging studies.

Despite the advanced age and clinical instability of these patients and the fact that many operations were performed on an emergency basis, nearly 9 in 10 patients survived operation. Operation precluded later rupture or worsening of the lesion. One could argue that aggressive aortic replacement might subject to operation patients with intramural hematomas that might heal spontaneously, but this consideration is far offset by the 5 documented late ruptures of intramural hematomas. Robbins et al ${ }^{12}$ recommended early surgical therapy for ascending aorta intramural hematoma; we have expanded our recommendations to all acutely presenting intramural hematomas because of the high propensity toward late rupture. We have not been able to identify presenting characteristics that can predict a stable radiographic or clinical course.

It is possible that catheter-based intra-aortic stent therapy may play a role in future management of these lesions. In favor of such an approach is the fact that these lesions are often limited in longitudinal extent and thus are amenable to stenting. On the other hand, these acute lesions result in a tenuous restraint of the bloodstream by only a fraction of the thickness of the aortic wall, and the trauma of the large catheters needed for stenting may pose a significant danger of rupture. Also, even with local control by stent, additional ulcers and hematomas may produce future rupture. Finally, the highly variable clinical courses of the natural disease processes will make assessment of true benefit from stenting difficult. Large numbers of patients and long follow-up times will be required. Although biologic glues have been suggested for the treatment of intramural hematomas, clinical experience is lacking. If a thoracotomy is necessary for delivery of glues, aortic resection may provide more definitive correction. As experience accumulates, understanding of the behavior of these disorders can progress from midterm to long-term courses.

\section{References}

1. Shennan T. dissecting aneurysms. Medical Research Council, special report series, No. 193. London: 1934.

2. Krukenberg E. Beitrage zur Frage des Aneurysma dissecans. Beitr Pathol Anat Allg Pathol. 1920;67:329-51.

3. Stanson AW, Kazmier FJ, Hollier LH, Edwards WD, Pairolero PC, Sheedy PF, et al. Penetrating atherosclerotic ulcers of the thoracic aorta: natural history and clinicopathologic correlation. Ann Vasc Surg. 1986;1:15-23.
4. Coady MA, Rizzo JA, Hammond GL, Pierce JG, Kopf GS, Elefteriades JA. Penetrating ulcer of the thoracic aorta: what is it? How do we recognize it? How do we manage it? J Vasc Surg. 1998;27:1006-16.

5. Coady MA, Rizzo JA, Elefteriades JA. Pathologic variants of thoracic aorta dissections: penetrating atherosclerotic ulcers and intramural hematomas. Cardiol Clin. 1999;17:637-57.

6. Ionescu AA, Vinereanu D, Wood A, Fraser AG. Periaortic fat pad mimicking an intramural hematoma of the thoracic aorta: lessons for transesophageal echocardiography. J Am Soc Echocardiogr. 1998;11: 487-90.

7. Muluk SC, Kaufman JA, Torchiana DF, Gertler JP, Cambria RP. Diagnosis and treatment of thoracic aortic intramural hematoma. $J$ Vasc Surg. 1996;24:1022-9.

8. Harris KM, Braverman AC, Gutierrez FR, Barzilai B, Davila-Roman VG. Transesophageal echocardiographic and clinical features of aortic intramural hematoma. J Thorac Cardiovasc Surg. 1997;114:619-26.

9. Vilacosta I, San Roman JA, Ferriros J, Aragoncillo P, Mendez R, Castillo JA, et al. Natural history and serial morphology of aortic intramural hematoma: a novel variant of aortic dissection. Am Heart J. 1997;134:495-507.

10. Porcellini M, Elia S, Camera L, Bracale G. Intramural hematoma of the thoracic aorta in octogenarians: is non operation justified? Eur J Cardiothor Surg. 1999;16:414-7.

11. Kaji S, Nishigami K, Akasaka T, Takagi T, Kawamoto T, Okura H, et al. Prediction of progression or regression of type A aortic intramural hematoma by computed tomography. Circulation 1999;100 Suppl: II281-6.

12. Robbins RC, McManus RP, Mitchell RS, Latter DR, Moon MR, Olinger GN, et al. Management of patients with intramural hematoma of the thoracic aorta. Circulation 1993;88(5 Pt 2):II1-10.

13. Krinsky G, Ribakove GH. Spontaneous progression of ascending aorta intramural hematoma to Stanford type A dissection fortuitously witnessed during an MR examination. J Comput Assist Tomogr. 1999; 23:966-8.

\section{Discussion}

Dr Thoralf Sundt (St Louis, Mo). The subject of penetrating atherosclerotic ulcers of the aorta has been addressed in the literature by only a few authors in the past, and the group from Yale is among them. I might add parenthetically that most of those articles have been in the vascular surgical literature, and we are therefore further indebted to you, Dr Elefteriades, for presenting this study in a cardiothoracic surgical forum.

Penetrating atherosclerotic ulcers are the subject of considerable controversy, as you have noted, with respect to radiologic definition as well as natural history and clinical management. With the aim of addressing the latter issues, in this study you included two related entities, penetrating ulcers and intramural hematomas, characterizing both as variant forms of aortic dissection.

At Washington University we have taken an alternative view. Although we agree that penetrating ulcers and intramural hematomas may be associated with one another, and indeed with frank dissection, we consider them to be distinct entities. Penetrating ulcers typically occur in the presence of extensive atherosclerotic disease, and we consider them to be diseases of the intima. By definition the ulcers penetrate into the media, and clearly they may be associated with intramural hematoma or dissection.

In contrast, we consider both intramural hematoma and dissection to be fundamentally diseases of the media, with most patients with dissection typically having little in the way of atherosclerotic disease. When penetrating ulcers lead to intramural hematoma or dissection, we consider them to be complicated ulcers. Because there is a greater body of literature already existing in the literature on intramural hematoma, I would like to focus on this fascinating entity, the penetrating ulcer. 
Dr Tarek Absi recently reviewed our experience with penetrating ulcers, drawing from both the radiologic and surgical databases. Dr Absi identified 36 patients with the diagnosis of penetrating ulcer, only 16 of whom had symptoms. The remainder were identified thanks to the remarkable advances made in high-resolution computed tomographic scanners, as you have noted. Of our 36 patients, only 6 ultimately required any surgical intervention. None of those patients without symptoms at presentation required surgery, and none have died subsequently of an aortic lesion.

My first question, then, is one of clarification. Were only symptomatic penetrating ulcers considered in your study by virtue of your source database? This preselection may influence the results of your study, predicting a more malignant natural history than the one we saw. A high percentage of your patients with ulcers, 38\%, had rupture at presentation. Perhaps this reflects a recognition in your community of your interest and expertise in this area. Do you think that the difference between our institutions in the apparent behavior of penetrating ulcers could be due to patient selection?

Second, again in the interest of defining natural history, could you clarify the fates of patients with penetrating ulcers who did not undergo operation at any point in time?

Third, you have stated that it is your policy to operate on penetrating ulcers and intramural hematomas whenever they involve the ascending aorta. If I understand your data correctly, however, only $83 \%$ of patients with penetrating ulcers involving the ascending aorta underwent operation, and only $45 \%$ of those with intramural hematomas underwent surgery. Could you clarify the reasons for nonoperative treatment in these cases?

Finally, given the availability currently of covered stent grafts for the thoracic aorta, what do you believe should be our recommendation for a patient found incidentally to have an uncomplicated penetrating ulcer of the descending thoracic aorta? Should a penetrating ulcer be covered as soon as it is identified?

Dr Elefteriades. Thank you, Dr Sundt, for those insightful comments and questions. You started out by discussing the degree to which these different entities are distinct or related. I do think that they are all in a spectrum, which is continuous. The key to grouping them together is that they are both flapless types of dissected pathologic lesions. Dr Kouchoukos once pointed out that the key is whether there is an intimal tear, and indeed these conditions do occur without an intimal tear, and they are both flapless, and the pathologists have known that for quite some time. As to how distinct they are from one other, there are occasions where it looks like a hematoma until you get more computed tomographic scan cuts, and then you may find that there is an ulcer around it. So I think that these entities are distinct but can overlap.

Next, you focused keenly on the question of symptomatic versus asymptomatic lesions. The patients on whose cases we are reporting were in the hospital. They had symptoms in a typical way, with chest pain with anterior phenomena and back and flank pain with descending phenomena. Asymptomatic lesions are occasionally called to our attention, as you pointed out. We get a call from the radiology department saying, "We have a patient here with an ulcer; what should we do?" And I do think that this is a different type of patient from the ones on whom we are reporting today, and they fall outside today's recommendations. I would like to point out, however, that I think penetrating ulcers are extremely dangerous. When one looks at a penetrating ulcer under the microscope, one is amazed by how the aorta holds together in light of the degree of adventitia remaining.

With respect to your question about the pattern of operation, my description that we tended to operate on lesions in the ascending aorta and tended to treat those in the descending aorta with anti-impulse therapy is an overall summary. As with the rest of the world, we are feeling the elephant to find out its contours and characteristics. So not everyone fell into that rubric. The other confounding factor is that a lot of these patients were elderly and had systemic contraindications to operation.

The numbers of patients not operated on who had serial radiographic follow-up were 15 with penetrating ulcers and 11 with intramural hematomas, making a total of 26 patients with serial radiographic follow-up.

Finally, I think that your point about the stent grafts is right on the money, because at times these are longitudinally relatively limited conditions that would seem to lend themselves to stent treatment. Drs Mitchell and Miller at Stanford have done incredible work with stent treatment of aortic conditions. I actually spoke with Dr Mitchell yesterday to get his view on this.

My response would be that there is some danger in treating these acute cases with the catheters necessary for stent graft placement. A catheter as big as your finger going into one of these patients with acute symptoms could pose some danger. Dr Mitchell was concerned that there might be incomplete therapy with a stent, because these are extremely diseased aortas, as you pointed out in your comments, and a different area besides the one covered might cause trouble.

I would like to say that the natural behavior of the thoracic aorta has to be followed up through the years. It is a highly variable, indolent process in many cases, and I think that if we do invoke stent therapy, it will take a reasonable number of patients followed up for a long time for us to know whether we have really made an impact on the natural history of these conditions.

Dr Joseph E. Bavaria (Philadelphia, $\mathrm{Pa}$ ). At the American Heart Association meeting 2 years ago, the Japanese group presented some data regarding type A intramural hematomas. They showed that if the ascending aorta was $5 \mathrm{~cm}$ or less, the patients did extremely well with medical therapy, and if it was $5 \mathrm{~cm}$ or more, they all did poorly and either required surgery or died of rupture. Could you comment on that algorithm?

Dr Elefteriades. That criterion of 5 or $5.5 \mathrm{~cm}$ is a general one that we agree is highly applicable for ascending aortic diseases. We have recommended a criterion of 5.5 for aneurysms in general. However, the relative benignity that you are describing is at variance with our experience.

Dr Paul Kurlansky (Miami Beach, Fla). I think that we all owe a debt of gratitude to Dr Elefteriades and the Yale group for teaching us about the natural history of aortic disease. My question regards the intramural hematoma group, in which approximately $45 \%$ of lesions healed and another $5 \%$ actually remained stable. Do you think that this presents a potential window for certain creative therapies, such as injection of various forms of biologic glue, to try to preclude the necessity for surgery in this group?

Dr Elefteriades. Yes, I think that you have hit on a weakness of the recommendation for generalized surgical therapy, because a 
few of the hematomas do heal and so perhaps could be treated nonoperatively. When we did this review, it actually changed our policy, because we did not realize how many of these patients had died. There were 5 with intramural hematomas who died during late follow-up. We looked back, and most of them had evidence of radiographic progression. But we consider the behavior pattern to be virulent enough that we do not want to take a chance on letting patients who were operative candidates be subject to that risk of rupture.

In terms of mechanisms to inject glue, I am not aware of any. I do not know quite how that would be done, but I think that it is an interesting proposal.

\section{ON THE MOVE?}

Don't miss a single issue of the journal! To ensure prompt service when you change your address, please photocopy and complete the form below.

Please send your change of address notification at least six weeks before your move to ensure continued service. We regret we cannot guarantee replacement of issues missed due to late notification.

\section{JOURNAL TITLE:}

Fill in the title of the journal here.

\section{OLD ADDRESS:}

Affix the address label from a recent issue of the journal here.

\section{NEW ADDRESS:}

Clearly print your new address here.

Name

Address

City/State/ZIP
COPY AND MAIL THIS FORM TO:

Mosby

Subscription Customer Service

6277 Sea Harbor Dr

Orlando, FL 32887
OR FAX TO:

407-363-9661

NM Mosby
OR PHONE:

800-654-2452

Outside the U.S., call

407-345-4000 